Case Report

\title{
Laparoscopic Common Bile Duct Exploration for Retrieval of Impacted Dormia Basket following Endoscopic Retrograde Cholangiopancreatography with Mechanical Failure: Case Report with Literature Review
}

\author{
J. W. O'Brien, ${ }^{1}$ R. Tyler, ${ }^{1}$ S. Shaukat, ${ }^{2}$ and A. M. Harris ${ }^{1}$ \\ ${ }^{1}$ Department of Laparoscopic and Upper Gastro-Intestinal Surgery, Hinchingbrooke Healthcare NHS Trust, Hinchingbrooke Park, \\ Huntingdon PE29 6NT, UK \\ ${ }^{2}$ Department of Gastroenterology, Hinchingbrooke Healthcare NHS Trust, Hinchingbrooke Park, Huntingdon PE29 6NT, UK
}

Correspondence should be addressed to J. W. O’Brien; james.obrien1@nhs.net

Received 7 January 2017; Accepted 13 June 2017; Published 13 July 2017

Academic Editor: Imran Hassan

Copyright (C) 2017 J. W. O’Brien et al. This is an open access article distributed under the Creative Commons Attribution License, which permits unrestricted use, distribution, and reproduction in any medium, provided the original work is properly cited.

\begin{abstract}
Dormia baskets are commonly used during endoscopic retrograde cholangiopancreatography (ERCP). One complication is basket retention, through impaction with a gallstone or wire fracture. We describe a case where the external handle of the basket snapped causing retained basket plus large gallstone impacted in the common bile duct (CBD). Following laparoscopic cholecystectomy, laparoscopic CBD exploration allowed direct stone fragmentation under vision with the choledochoscope. Fragments were removed using a choledochoscopic basket and Fogarty catheter, and the basket was withdrawn. Literature search identified 114 cases of retained baskets with management including shockwave lithotripsy (27\%), papillary balloon dilatation (22\%), open CBD exploration (11\%), and one laparoscopic case.
\end{abstract}

\section{Introduction}

ERCP is used for relieving biliary obstruction caused by choledocholithiasis $[1,2]$. Stone removal can be performed with a Dormia basket or balloon catheter, an approach that extracts up to $90 \%$ of CBD stones successfully $[3,4]$. Dormia baskets most commonly consist of four stainless steel wires arranged at 90 degrees radially that are opened onto a stone to allow capture. When a stone is too big to be removed via the papillary orifice, some models permit mechanical lithotripsy, and rescue mechanical lithotripters are available for impaction. This has a success rate of $79 \%$ to 92\% [5-8]. Overall complications of mechanical lithotripsy are between $6 \%$ and $13 \%$, with basket impaction or wire fracture contributing up to $4 \%[5,6,9]$. Retention of a Dormia basket in the biliary tree is a recognised complication [2]. This may be due to capture of a stone that is too large to permit removal, with subsequent impaction of the basket and stone. Alternatively, retention through loss of the ability to manipulate the basket can occur through fracture of the wires of the Dormia basket itself or fracture of a mechanical lithotripter, which can occur at an extraor intracorporeal level. The impacted Dormia can cause cholangitis, pancreatitis, or migration, and no consensus exists on the optimal technique for removal [10]. We present laparoscopic management for a case of retained Dormia and review the available literature.

\section{Case Report}

A 67-year-old Caucasian female with a body mass index of 30 was referred to clinic with symptoms of biliary colic. Past medical history included type 2 diabetes mellitus, hypertension, asthma, and previous total abdominal hysterectomy. Regular medications included bendroflumethiazide, metformin, omeprazole, ramipril, salbutamol, and simvastatin. She was a nonsmoker with minimal alcohol intake. Abdominal examination was normal and there were no signs 


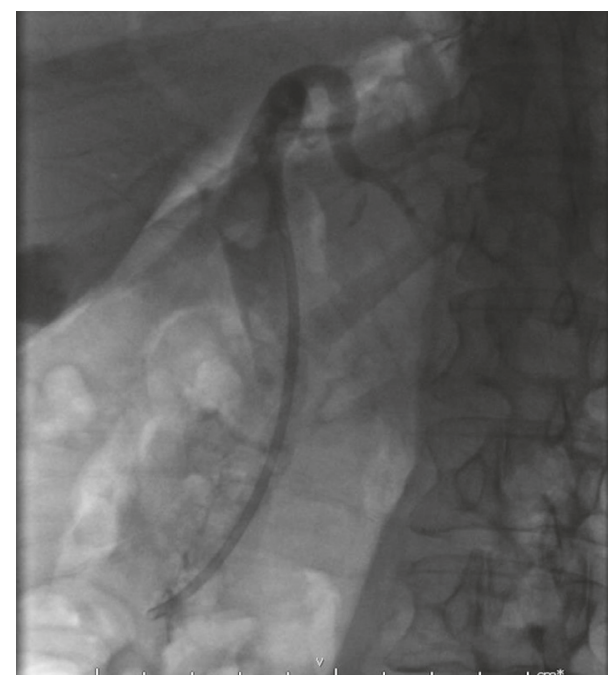

FIGURE 1: Gallstone seen near top of common bile duct.

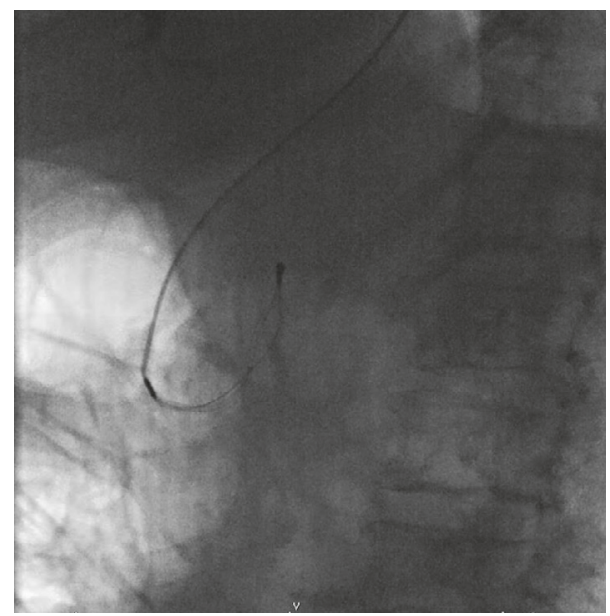

FIGURE 2: Dormia basket in CBD, after handle has broken (endoscope has been removed pending urgent surgery).

of jaundice or anaemia. Ultrasound imaging revealed a common bile duct diameter of $13 \mathrm{~mm}$, containing a $12 \mathrm{~mm}$ stone. Liver function tests showed bilirubin $13(<21 \mathrm{mg} / \mathrm{dl})$, alanine transaminase $26(\leq 34 \mathrm{IU} / \mathrm{L})$, and alkaline phosphatase 46 (20-140 IU/L). She underwent an ERCP with sphincterotomy, placement of a straight stent, and removal of several stones. One large stone that could not be removed with the Dormia basket was left in situ. During repeat ERCP three weeks later the large CBD stone (Figure 1) was engaged in a Dormia basket for mechanical lithotripsy but on cranking the lithotripter handle the wires snapped externally at the mouth (Figure 2). The patient was referred to upper gastrointestinal surgery and was taken as an emergency to the operating theatre the same day. A two-stage approach was taken following laparoscopic cholecystectomy. A $5 \mathrm{~mm}$ choledochoscope was introduced via a longitudinal choledochotomy and confirmed the presence of an impacted basket plus large stone at the ampulla (Figure 3). The choledochoscope itself was

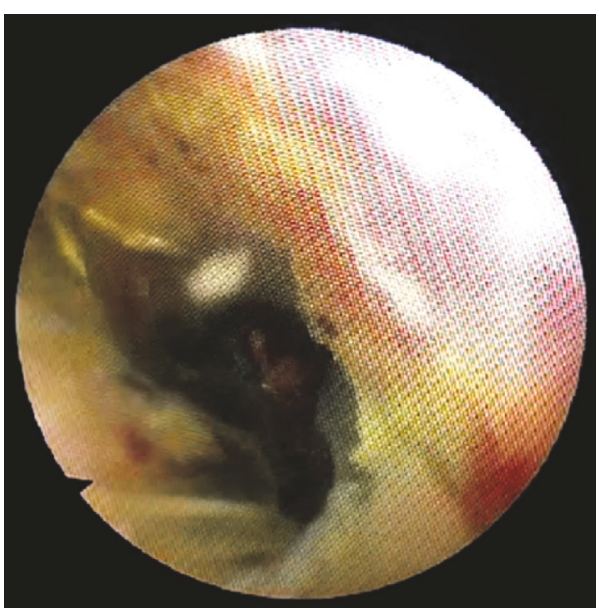

FIGURE 3: Choledochoscopic view of distal CBD. Large stone is seen within impacted ERCP Dormia basket.

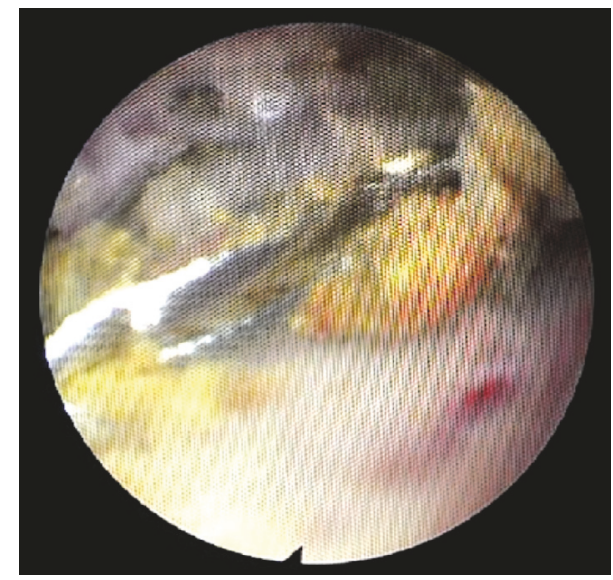

FIGURE 4: Debulked ERCP Dormia basket now collapsed and ready for removal, with few remaining stone fragments.

gently used to fragment the engaged stone into smaller pieces under direct vision. Next, a Fogarty balloon catheter and second Dormia basket (Cook Medical, Ireland) were used via the choledochoscope to remove most of the stone fragments laparoscopically. Having debulked the stone load (Figure 4), it was then possible to gently deliver the ERCP Dormia basket back into the duodenum without complication, which could then be removed orally. CBD clearance was confirmed and the choledochotomy closed with a 3-0 Vicryl continuous suture. After ERCP the patient was readmitted with acute pancreatitis and was hospitalised for 10 days, following which she made a full recovery.

\section{Discussion}

An extensive search of the English language literature in PubMed and MEDLINE ${ }^{\circledR}$ from 1950 onwards, including references, was carried out to obtain all published cases of retained biliary extraction baskets during ERCP for biliary or pancreatic stones. Search terms were "Dormia" or "basket" 
and "endoscopic retrograde cholangiopancreatography" or "ERCP". 46 publications were identified, which included a total of 114 cases. One large case series by Thomas et al. (31 patients) [9] was not included in the following calculation because management of additional non-Dormia related complications was not described separately, leaving 83 cases. There were $42(51 \%)$ cases of retention due to basket impaction on an impacted stone, without any wire fracture. There were 41 (49\%) cases of basket retention due to wire fracture. $14(34 \%)$ of the wire fractures were described subsequent to basket impaction. The wire fractures occurred extracorporeally, at the handle of a mechanical lithotripter in $13(32 \%)$ and intracorporeally, along the guide wire or basket wires in 28 (68\%), 25 of which were mechanical lithotripter wires. When specified, the $\mathrm{CBD}$ was the site of retention in $83 \%$ of cases.

The retained baskets were retrieved by a variety of strategies: extracorporeal shockwave lithotripsy (22), balloon dilatation (18), open surgery (9), a second Dormia basket (10), rescue mechanical lithotripter (5), exchange of metal wires (5), conservative management (2), exchange of metal sheaths (2), extension of sphincterotomy (2), laparoscopic surgery (2), laser lithotripsy (2), rat tooth forceps (2), goose neck snare (1), and papillotome to the stone (1). Each patient underwent an average of 1.4 procedures (including the original ERCP). In 33 papers (42 patients) definitive management of the common bile duct was described. $28(67 \%)$ of these patients needed at least one further procedure to manage their choledocholithiasis following the ERCP, and 6 (14\%) needed more than one further procedure. The average total number of extra procedures required to definitively manage choledocholithiasis per patient following ERCP was 0.67.

Recent case series report impaction of a Dormia basket during ERCP in as few as $0.6 \%$ and $0.8 \%$ of cases. Previously, it was reported in as many as $5.9 \%$ of cases [11-15]. Certain techniques increase the risk of basket retention. In one multicentre study of 31 patients, overall complications were three times higher following mechanical lithotripsy for pancreatic stones (11.6\%) compared to biliary stones (3.6\%), with fracture of the basket the most common complication [9]. Stone impaction, stone size, and a stone to bile duct diameter ratio greater than one are predictors of failed mechanical lithotripsy [5, 13]. Stone size over $20 \mathrm{~mm}$ is suggested as a contraindication for ERCP by some authors [16], but others suggest the ratio, which is increased by previous cholecystitis and cholangitis, is as important [5]. In such cases, García-Gallont et al. recommend using alternative methods as soon as the Dormia basket begins to deform in the stiffened common bile duct [17]. Typically basket impaction is encountered at the ampulla but case of impaction at the distal pancreatic duct in chronic pancreatitis is described [18] and less commonly the hepatic ducts [19] and a single case within the gallbladder itself [20].

The most commonly described management of an impacted Dormia basket is extracorporeal shock wave lithotripsy, perhaps reflecting the high proportion of cases reported from European centres. This results in high clearance after one session (92\%), but subsequent endoscopy may be necessary to remove stone fragments and achieve definitive duct clearance $[9,12]$. In the event of failure of laser lithotripsy, repeat laser shock wave lithotripsy is required with surgical exploration recommended if further lithotripsy fails [21]. Although the basket is visible under fluoroscopy, if cannulation of the bile duct is necessary for visualisation, this can be difficult if an impacted Dormia with stone is obstructing the distal bile duct. Importantly, such techniques are only available in certain centres, which can result in delays whilst the patient is transferred. Any delay in management can increase the severity of any subsequent pancreatitis, cholangitis and sepsis.

Rescue papillary balloon dilatation is an option if it has not already been carried out prior to basket impaction. The overall rate of bleeding following ERCP is 1.3\% [22] and metaanalyses describe a similar $1.2 \%$ rate following combined sphincterotomy and balloon dilatation [23]. In a small case series six impacted baskets were successfully managed with balloon dilatation [15]. All six were done by the same tertiary centre endoscopist. Given the risk of perforation previously reported following balloon dilatation [24], this highlights the importance of specialist ERCP referral in such cases. Extreme care needs to be taken when using monopolar devices to extend the sphincterotomy in order to deliver an impacted basket, due to the risk of thermal injury caused by heat conduction through exposed basket wires [25].

Rescue mechanical lithotripsy was utilised successfully in five cases of retained Dormia. One centre describes four cases of impacted stone and Dormia successfully managed with "through the endoscope" rescue lithotripsy [26]. However, mechanical lithotripsy itself is associated with basket retention and wire fracture. $89 \%$ of intracorporeal wire fractures occurred along mechanical lithotripsy wires, and, similar to the case we report, there were 12 cases reporting lithotripsy handle fracture. Equipment failures occurred during use of "through the endoscope" and external or rescue mechanical lithotripters. There are not enough equipment details supplied in the literature to attempt subanalysis.

In $1993 \mathrm{Ng}$ et al. described laparoscopic retrieval (via cholecystotomy) of a basket inadvertently impacted within the gallbladder itself but suggested that retention in the biliary tree was not amenable to laparoscopic rescue [20]. Laparoscopic common bile duct exploration, conducted in experienced centres, established itself in the late 1990s, showing similar success rates and morbidity to ERCP $[27,28]$. Laparoscopic retrieval was first described in 2000 by Ainslie et al. [29]. This is only the second case to describe successful laparoscopic rescue. There was no mortality reported following open surgical management of a retained basket, which was the third most common method of retrieval in the literature.

\section{Conclusion}

This review describes the established risk of basket retention in the bile duct when using mechanical lithotripsy during therapeutic ERCP and further highlights a range of scenarios which may present to the endoscopist, including basket retention due to wire fracture. In centres with appropriate 
equipment, extracorporeal shockwave lithotripsy and papillary balloon dilatation for retained baskets are described in the literature, with minimal further procedures required to ensure treatment of choledocholithiasis. We describe a single operative treatment whereby, following laparoscopic cholecystectomy, laparoscopic CBD exploration via choledochotomy allowed retrieval of the retained basket and confirmation of duct clearance with choledochoscopy. We have shown the approach to be both feasible and safe and, where surgical expertise permits, can reduce the risk of further treatment sessions to manage residual common bile duct stones or debris. When encountering difficult (large or impacted) common bile duct calculi the endoscopist should consider which options are available at their institution in the event that a basket complication is encountered.

\section{Consent}

The authors confirm that written informed consent was obtained from the patient for publication of this case report and accompanying images.

\section{Conflicts of Interest}

The authors declare that there are no conflicts of interest regarding the publication of this paper.

\section{References}

[1] D. G. Adler, T. H. Baron, R. E. Davila et al., "ASGE guideline: the role of ERCP in diseases of the biliary tract and the pancreas," Gastrointestinal Endoscopy, vol. 62, no. 1, pp. 1-8, 2005.

[2] D. G. Adler, J. D. Conway, F. A. Farraye et al., "Biliary and pancreatic stone extraction devices," Gastrointestinal Endoscopy, vol. 70, no. 4, pp. 603-609, 2009.

[3] N. Fujita, H. Maguchi, Y. Komatsu et al., "Endoscopic sphincterotomy and endoscopic papillary balloon dilatation for bile duct stones: a prospective randomized controlled multicenter trial," Gastrointestinal Endoscopy, vol. 57, no. 2, pp. 151-155, 2003.

[4] D. L. Carr-Locke, "Therapeutic role of ERCP in the management of suspected common bile duct stones," Gastrointestinal Endoscopy, vol. 56, no. 6, pp. S170-S174, 2002.

[5] P. K. Garg, R. K. Tandon, V. Ahuja, G. K. Makharia, and Y. Batra, "Predictors of unsuccessful mechanical lithotripsy and endoscopic clearance of large bile duct stones," Gastrointestinal Endoscopy, vol. 59, no. 6, pp. 601-605, 2004.

[6] W.-H. Chang, C.-H. Chu, T.-E. Wang, M.-J. Chen, and C.C. Lin, "Outcome of simple use of mechanical lithotripsy of difficult common bile duct stones," World Journal of Gastroenterology, vol. 11, no. 4, pp. 593-596, 2005.

[7] J. C. Vij, M. Jain, K. K. Rawal, R. A. Gulati, and A. Govil, "Endoscopic management of large bile duct stones by mechanical lithotripsy,' Indian J Gastroenterology, vol. 14, no. 4, pp. 122-123, 1995.

[8] M. J. Shaw, R. D. Mackie, J. P. Moore et al., "Results of a multicenter trial using a mechanical lithotripter for the treatment of large bile duct stones," Am J Gastroenterology, vol. 88, no. 5, pp. 730-733, 1993.

[9] M. Thomas, D. A. Howell, D. Carr-Locke et al., "Mechanical lithotripsy of pancreatic and biliary stones: Complications and available treatment options collected from expert centers," American Journal of Gastroenterology, vol. 102, no. 9, pp. 18961902, 2007.

[10] P. Ranjeev and K.-L. Goh, "Retrieval of an impacted Dormia basket and stone in situ using a novel method," Gastrointestinal Endoscopy, vol. 51, no. 4, part 1, pp. 504-506, 2000.

[11] M. U. Schneider, W. Matek, R. Bauer, and W. Domschke, "Mechanical lithotripsy of bile duct stones in 209 patients-effect of technical advances," Endoscopy, vol. 20, no. 5, pp. 248-253, 1988.

[12] G. Sauter, M. Sackmann, J. Holl, J. Pauletzki, T. Sauerbruch, and G. Paumgartner, "Dormia baskets impacted in the bile duct: Release by extracorporeal shock-wave lithotripsy," Endoscopy, vol. 27, no. 5, pp. 384-387, 1995.

[13] S. H. Lee, J. K. Park, W. J. Yoon et al., "How to predict the outcome of endoscopic mechanical lithotripsy in patients with difficult bile duct stones?" Scandinavian Journal of Gastroenterology, vol. 42, no. 8, pp. 1006-1010, 2009.

[14] W. H. Schreurs, J. R. Juttmann, W. N. H. M. Stuifbergen, H. J. M. Oostvogel, and T. J. M. V. Vroonhoven, "Management of common bile duct stones: short- and long-term results with selective endoscopic retrograde cholangiography and endoscopic sphincterotomy," Surgical Endoscopy and Other Interventional Techniques, vol. 16, no. 7, pp. 1068-1072, 2002.

[15] P. Katsinelos, K. Fasoulas, A. Beltsis et al., "Large-balloon dilation of the biliary orifice for the management of basket impaction: A case series of 6 patients," Gastrointestinal Endoscopy, vol. 73, no. 6, pp. 1298-1301, 2011.

[16] N. Fukino, T. Oida, A. Kawasaki et al., "Impaction of a lithotripsy basket during endoscopic lithotomy of a common bile duct stone," World Journal of Gastroenterology, vol. 16, no. 22, pp. 2832-2834, 2010.

[17] R. García-Gallont, J. S. Velasquez, and W. Duarte, "Surgical removal of a severed Dormia basket from the bile duct," Endoscopy, vol. 46, no. 1, pp. E20-E21, 2014.

[18] A. F. Cutler, W. Mark Hassig, and T. T. Schubert, "Basket impaction at the pancreatic head," Gastrointestinal Endoscopy, vol. 38, no. 4, pp. 520-521, 1992.

[19] J. Sheridan, T. M. Williams, E. Yeung, C. Ho, and W. Thurston, "Percutaneous transhepatic management of an impacted endoscopic basket," Gastrointestinal Endoscopy, vol. 39, no. 3, pp. 444-446, 1993.

[20] W. Ng, M. Yiu, and K. Lee, "Impaction of a stone basket in the gallbladder with laparoscopic rescue," Gastrointestinal Endoscopy, vol. 39, no. 2, pp. 217-218, 1993.

[21] T. Attila, G. R. May, and P. Kortan, "Nonsurgical management of an impacted mechanical lithotriptor with fractured traction wires: endoscopic intracorporeal electrohydraulic shock wave lithotripsy followed by extra-endoscopic mechanical lithotripsy," Canadian Journal of Gastroenterology, vol. 22, no. 8, pp. 699-702, 2008.

[22] A. Andriulli, S. Loperfido, G. Napolitano et al., "Incidence rates of post-ERCP complications: a systematic survey of prospective studies," The American Journal of Gastroenterology, vol. 102, no. 8, pp. 1781-1788, 2007.

[23] G. C. Meine and T. H. Baron, "Endoscopic papillary largeballoon dilation combined with endoscopic biliary sphincterotomy for the removal of bile duct stones (with video)," Gastrointestinal Endoscopy, vol. 74, no. 5, pp. 1119-1126, 2011.

[24] Y. S. Lee, J. H. Moon, B. M. Ko et al., "Endoscopic closure of a distal common bile duct perforation caused by papillary 
dilation with a large-diameter balloon (with video)," Gastrointestinal Endoscopy, vol. 72, no. 3, pp. 616-618, 2010.

[25] F. Ekıı, O. Yüksel, O. Üsküdar, İ. Yüksel, A. Altinbaş, and Ö. Başar, "Successful endoscopic removal of fractured basket traction wire during mechanical lithotripsy," Turk J Gastroenterology, vol. 22, no. 2, pp. 233-234, 2011.

[26] M. Matsushita, H. Takakuwa, Y. Matsubayashi et al., "Throughthe-endoscope technique for retrieval of impacted biliary baskets with trapped stones," American Journal of Gastroenterology, vol. 99, no. 6, pp. 1198-1199, 2004.

[27] M. Rhodes, L. Sussman, L. Cohen, and M. P. Lewis, "Randomised trial of laparoscopic exploration of common bile duct versus postoperative endoscopic retrograde cholangiography for common bile duct stones," The Lancet, vol. 351, no. 9097, pp. 159-161, 1998.

[28] A. Cuschieri, E. Lezoche, M. Morino et al., "E.A.E.S. multicenter prospective randomized trial comparing two-stage vs singlestage management of patients with gallstone disease and ductal calculi," Surgical Endoscopy, vol. 13, no. 10, pp. 952-957, 1999.

[29] W. Ainslie, J. Reed, and M. Larvin et al., "Successful laparoscopic rescue of an impacted lithotriptor basket from the common bile duct," Endoscopy, vol. 32, 2000. 


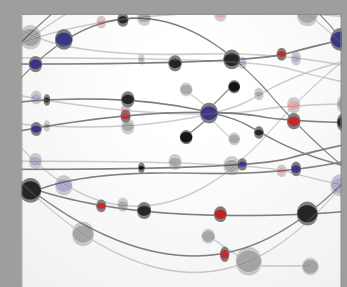

The Scientific World Journal
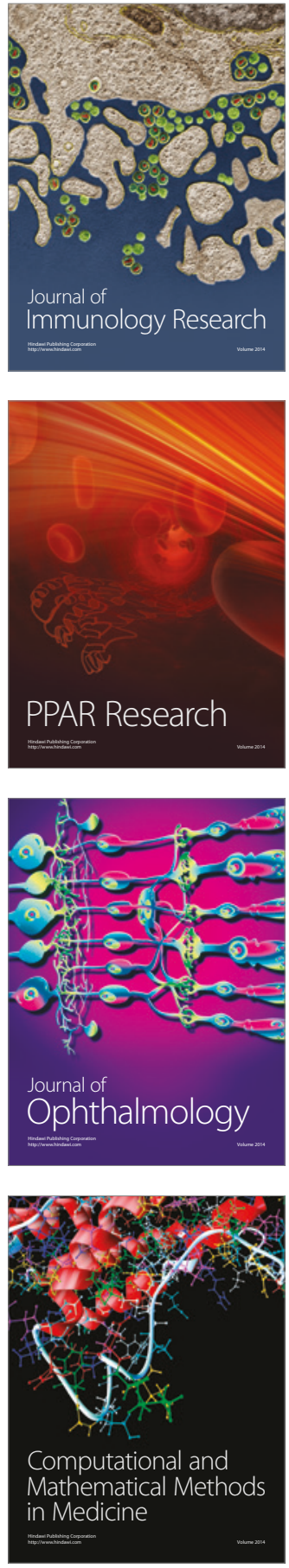

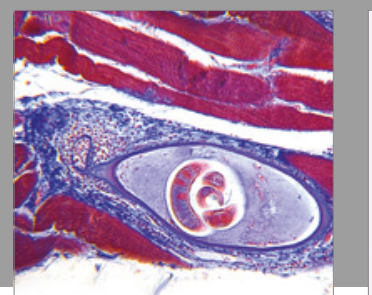

Gastroenterology Research and Practice
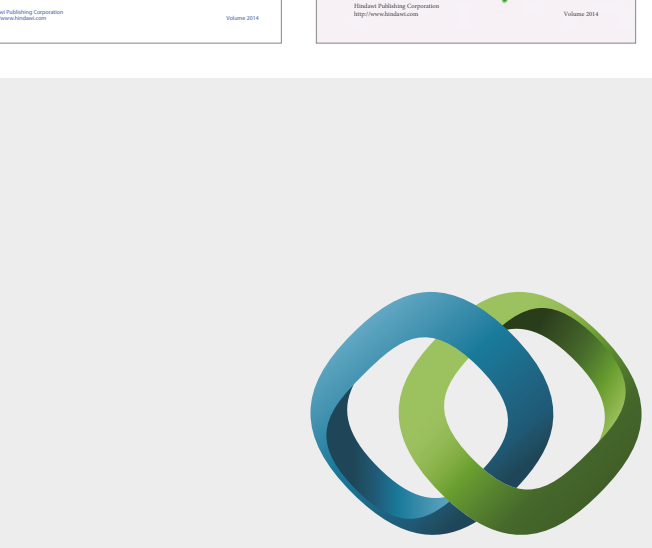

\section{Hindawi}

Submit your manuscripts at

https://www.hindawi.com
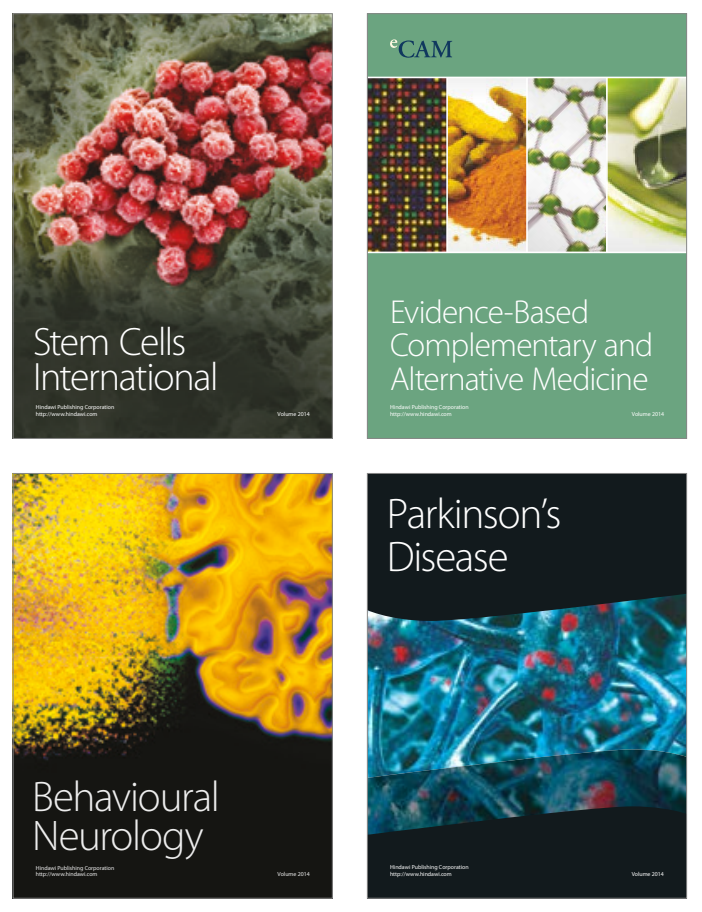
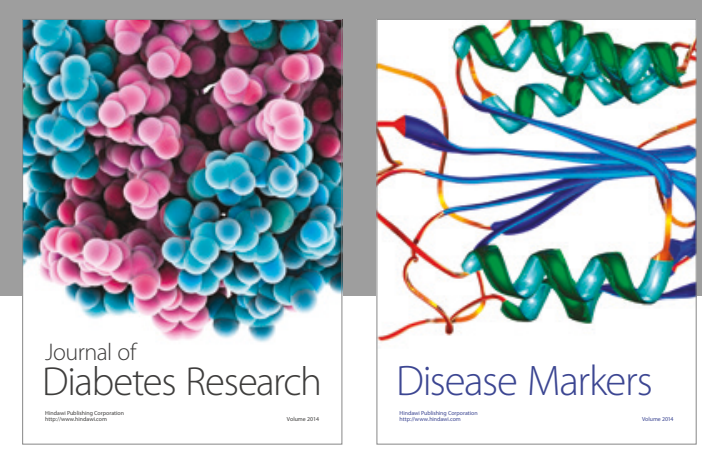

Disease Markers
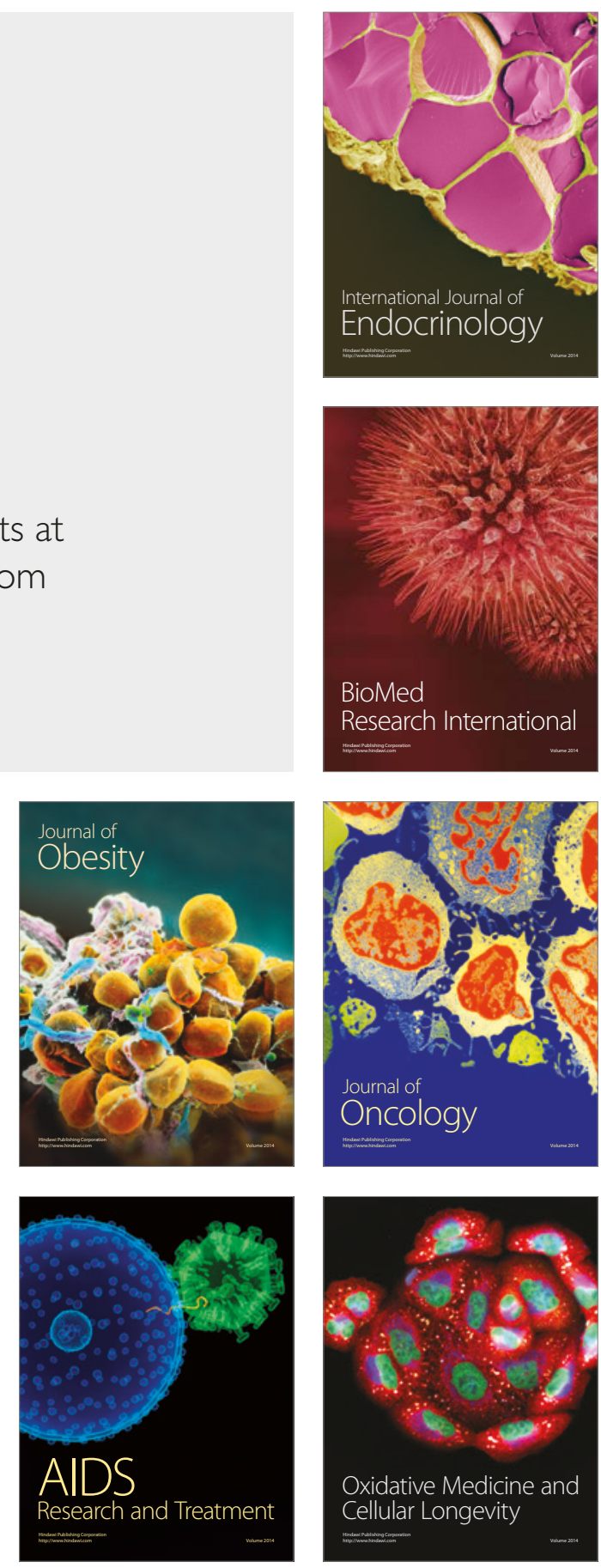